\title{
Effect of Classroom Interaction Patterns on Secondary School Students Cognitive Achievement in Biology
}

\author{
Nneka Rita Nnorom, Phyllis Osas Erhabor \\ Department of Science Education \\ Chukwuemeka Odumegwu Ojukwu University, Uli \\ Nigeria
}

\begin{abstract}
The study examined the effect of classroom interaction patterns on secondary school students, cognitive achievement in Biology in Edo State, Nigeria. Two research questions and two null hypotheses guided the study. The design of the study was a quasi-experimental, pre-test, post-test, nonequivalent control group design. A sample of 270 SSI biology students randomly drawn from six public coeducational secondary schools in Ikpoba Okha Education zone of Edo state were used for the study. An instrument known as Biology Achievement Test (BAT) was used for the study. The instrument was validated, and the reliability coefficient was established using Kudder Richardson K-R 20 and was found 0.87. The data collected were analysed using mean and standard deviation. Analysis of covariance (ANCOVA) was used to test the hypotheses at .05 level of significance. The results revealed that students taught with classroom interaction patterns perform better than those taught with conventional method, also gender has no significant difference in the mean cognitive achievement scores in biology due to application of classroom interaction patterns. Based on the findings, recommendations were made.
\end{abstract}

\section{Introduction}

Science and technology have proved significantly useful in man's daily struggle to control his environment and the world around him. Most developing nations as a result of visible role of science and technology now make frantic efforts to improve on the study of science and other allied subjects in their schools. Included among the basic science subjects is biology.

Biology occupies a unique position in the secondary school education curriculum because of its importance as science of life. In Nigeria, the secondary school biology curriculum is designed to promote students' investigation into natural phenomena, to deepen students' understanding and interest in biological sciences and also to encourage students' ability to apply scientific knowledge to everyday life in matters of personal, community, health and agriculture among others (Federal Ministry of Education, 2009). It is a prerequisite subject for many fields of learning, and that contributes immensely to the technological growth of the nation. Biology is introduced to students at senior secondary school level as a preparatory ground for human development, where career abilities are groomed, potentials and talents are discovered and energized (Federal Republic of Nigeria, 2015). Biology has a very high enrollment of Students in Senior Secondary Certificate Examination (SSCE) than physic and chemistry. This clearly manifested itself in the Senior Secondary School Certificate taken every year [20]. Therefore, the quality and quantity of biology education like science education received by the Secondary school students would be focused towards the development of future scientist. As Amosa, Akawo, Eli and Queen (2014) noted that biology would help to develop future scientist, technologist, engineers and other related professions. A sound knowledge of biology is a prerequisite factor for entrance into such professions like medicine, pharmacy, nursing, agriculture, forestry, biotechnology, nanotechnology and so on [8]. This clearly shows that biology is very important to any growing economy.

Despite the importance of biology as one of a key subject in realizing any nation's scientific and technological aspirations, evidence of low achievement in the subject by Nigerian students abound (Chief Examiners' Report, 2010 - 2015) See fig. 1. The implication of this is that Nigeria may have shortages of manpower in the area of science and technology, which may affect Nigeria's achievement of vision 2010 to become one of the 20 industrialized nations in the world.

\begin{tabular}{|llll|}
\hline Year & Enrolled Students & Distinction/Credit (\%) & Pass/Failure (\%) \\
\hline 2010 & $1,203,028$ & $466,155(38.75)$ & $736913(61.25)$ \\
2011 & $1,374,050$ & $492,422(35.84)$ & $881628(64.16)$ \\
2012 & $5,135,288$ & $488,302(9.51)$ & $4646986) 90.49)$ \\
2013 & 609,026 & $96,202(15.79)$ & $512824(84.20)$ \\
2014 & 841,863 & $36,348(4.32)$ & $805515(95.68)$ \\
2015 & $1,036,520$ & $322,310(31.10)$ & $714210(68.90)$ \\
\hline
\end{tabular}

Source: West African Examination Council 2010 - 2015 Annual Report [19]

Figure 1. Statistics of students' enrollment and performance in Biology in May/June WASCE $(2010-2015)$ 
From Figure 1 result, it shows that in 2012, only 9.51 percent scored distinction and credit and 90.49 percent had pass and fail grades. None of the results from 2010 to 2015 recorded up to 40 percent distinction/credit. This was attributed to poor instructional strategy and subsequently poor cognitive achievement.

Achievement, according to Aniaku [3] is the quantity and quality of knowledge and skill an individual or groups acquired about a specific area of course and how that knowledge can be made use of in solving societal problems. It is however, the accomplishment of academic goals, the educational outcomes of students, the extent a student, a teacher or an instructor has achieved the stated objectives [3]. There is however no doubt that students' achievement is influenced by the teachers' teaching methods. This was observed by Okoyefi and Nzewi [15] who noted that teachers' teaching methods increased students' cognitive achievement in science subjects. Similarly, Opara [17] noted that teachers' method of teaching influenced students' cognitive achievement in science. Students vary in their academic abilities and this tends to be reflected in the extent to which they are affected by a particular teaching method. Various teaching methods are used by teachers in the teaching of biology aimed at bringing about meaningful learning. These include conventional method, lecture method, demonstration method, project among others. According to Awotua-Efeby [5], the conventional method is mainly teacher centered with student being consistently passive and content are taught as absolute knowledge. Unfortunately, evidence from literature showed that most science teachers in Nigeria secondary schools predominantly use conventional method in teaching science due to poor knowledge and no exposure to other learner centered method leading to poor cognitive achievement [2], [16]. Hence, there is need for an improved instructional strategy like application of classroom interaction patterns.

The issue of gender and biology achievement has attracted attention of some researchers [11]. The arbitrary assigning roles and the expectations to different sex (male and female) within the society has given rise to such misconception of perceiving science as masculine and male domain only. The problem is even compounded by the fact that most science educators give masculine outlook to science subjects such as physics and chemistry, encouraging females to go rather for biology, agriculture science and home economics which they consider to be more female-friendly science subjects. Some other researchers Okoyefi and Nzewi [15] are of the opinion that gender has no influence on students rather, student achieved equally when given equal opportunity. Hence, the researchers considered it necessary to explore the influence of gender on cognitive achievement of biology students when exposed to integrative application of interaction patterns.

Integrative application of all the plausible classroom interaction patterns is what is called whole-class interactive teaching [13]. Also, Ogbu [13] noted that the predominant way in which classroom interaction occurs is called interaction pattern. Interaction pattern is a way in which messages are transmitted successfully between teachers and students to achieve instructional objective in the classroom [18], [9]. Whole classroom interactive teaching using interaction patterns is an instructional strategy whereby the teacher consciously and skillfully plans and executes every of his lesson so that the interaction patterns are plausibly and effectively applied per instant in each of lesson delivery. Classroom interaction is the sum total of activities taking place in the classroom between the teacher, the learner and the learning materials during the teaching process [6]. Classroom interaction pattern when applied properly is mainly student-centered, with students consistently very active and the teacher a facilitator. Mackey [6] also asserts that 'through the process of repetition, segmentation and rewarding, interaction can serve to draw learners' attention to form meaningful relationship and provide them with additional time to focus on encoding manning". According to Nurmasita [12] analysis of classroom interaction may be seen as an instrument which is designed to record categories of interaction during, or from, recorded teaching or learning session. It can be used for studying the chain of classroom events in such a fashion that each event is taken into consideration.

The four major classification of classroom interaction patterns according to Ogbu [13] are thus:

- Teacher-student interaction pattern: an interaction between the teacher and individual students or group of students.

- Students-students interaction pattern: that is where students reacts to each others actions attitude and opinions during class session, it is further classified as co-operative, competitive and individualistic interaction pattern.

- Teacher-material interaction pattern: that is when the teacher is manipulating instructional materials, machines and equipments for the purpose of skill learning or in other to stress a point or clarify some issues for the students.

- Students-material interaction pattern: when students look on instructional materials, machines and equipment solve practical problems or experiment with specimen or models.

Classroom interaction pattern is an instructional strategy whereby the teacher ensures that the above interaction patterns are effectively applied in each lesson delivery. By this strategy, the teacher ensures that only the advantages of each classroom 
interaction are fully tapped, skillfully skipping their disadvantages. The question now is: can integrative application of classroom interaction patterns serve as an improved and more effective instructional strategy that can lead to students improved cognitive achievement in biology?

\section{Purpose of the Study}

The main purpose of this study was to find out the effect of classroom of interaction patterns on secondary school students' cognitive achievement in biology. Specifically, the study will:

1. Determine the effect of application of classroom interaction patterns and conventional method on students' cognitive achievement in biology.

2. Ascertain the effect of application of classroom interaction pattern of male and female students on cognitive achievement in biology.

\section{Research Questions}

The following research questions were formulated to guide the study:

1. What is the effect of classroom interaction patterns and conventional method on students' mean cognitive achievement in biology?

2. What are the mean cognitive achievement scores of male and female students exposed to different classroom interaction patterns?

\section{Hypotheses}

The following null hypotheses were formulated to guide this study:

1. The mean cognitive achievement scores of students taught with classroom interaction pattern will not differ significantly from those taught with conventional methods.

2. There is no significant difference in the mean cognitive achievement scores of male and female students in biology due to application of classroom interaction patterns.

\section{Method}

The study adopted the quasi experimental design. Specifically, the pre-test, post-test, non-equivalent control group design. The study was conducted within the Ikpoba Okha Education zone of Edo State. The sample for the study comprised of two hundred and seventy (270) SSI biology students drawn from six public co-educational secondary schools in the zone. The six co-educational secondary schools were drawn through a stratified random sampling. In each school, one intact-class was drawn for the study through simple random sampling. Out of the six coeducational schools, three schools were assigned to the treatment group while the remaining three were assigned to the control group. The assignment of the schools to the treatment and control groups was done through a stratified random sampling. For the experimental group a total of one hundred and twenty-seven (127) students were used (58 males and 69 females), then for the control group one hundred and forty-three (143) students were used (83 female and 63 male).

The instrument used for data collection was the Biology Achievement Test (BAT) which has 20 items developed by the researchers, based on the biology topic "Unit of Life" which was from SSI biology curriculum. Face and content validity of the instrument were established by three experts from science education and measurement and evaluation from Chukwuemeka Odumegwu Ojukwu University, Nigeria. The internal consistency reliability coefficient was established using Kudder Richardson $\mathrm{K}-\mathrm{R} 20$ and was found .87 .

\section{Experimental Procedure}

The regular biology class teachers were used for the study. Training was giving to biology teachers who took the experimental group on the application of various classroom interaction pattern while the biology teachers who took the control group used the conventional method. Since intact classes were used. The experimental stream teachers were given notes of lesson prepared by the researchers while the researchers vetted the lesson plan prepared by the biology teachers in the control group to ensure that the teachers did not deviate from the procedures of instructions commonly used by the biology teachers. Biology Achievement Test was used for both pre-test and post-test. Before the onset of the experiment, subjects in both treatment and control groups were given the pre-test.

The treatment consists of teaching the biology concept: 'unit of life' using classroom interaction patterns. Four major approaches of classroom interaction patterns were employed namely: teacherstudents interaction pattern, student-student interaction pattern, teacher-material interaction pattern and student-material interaction pattern.

In teacher-student interaction pattern, the teacher introduces the topic and move into interaction section with the students either individually or as a group, here, the teacher do more of explaining while she listens to the students. The students are more active while the teacher is passive.

In students-students interaction pattern, the students reacts to each others action, attitude and opinion as the class proceeds. Here the teacher gives the students tasks to perform as a group and then later individually. The students were allowed to communicate their ideas and findings as members of 
the group. The teacher went around supervising what they are doing, acting as a guide.

In teacher-material interaction pattern, the teacher presents to the students an instructional material as regards to the topic of discussion for the purpose of skill learning or in other to stress a point or to clarify some issues for the students.

In students-material interaction pattern, the students are allowed to work on the instructional materials provided by the teacher. The teacher divides the students into five groups, shares the instructional materials among the groups and ask the students to solve practical problems or experiment with it. The students were advised to consult their teachers when any difficulty relating to the concept under study arises but not teaching them.

For the control group, the conventional method was used in teaching the subjects in the sample schools. In this method, the teacher verbalized the relevant concept and principles during the lesson. The student watched and listened attentively, taking down relevant notes. The teaching of both experimental and control group was done during the normal school biology periods following the normal timetable of the school.

At the end of 6 weeks, the teacher administered the post-test (after reshuffling of the items) to the subjects. The scripts from both pre-test and post-test of the two groups were marked and scored using the marking guide. The data collected from pre-test and post-test were analysed using mean and standard deviation for answering the research questions, analysis of covariance (ANCOVA) for testing the hypotheses at $0.05 \%$ of confidence.

\section{Results}

\section{Research question 1}

What is the effect of classroom interaction patterns and conventional method on students' mean cognitive achievement in biology?

Table 1. Mean and Standard deviation for the experimental and control groups

\begin{tabular}{|c|c|c|c|c|c|c|}
\hline & & \multicolumn{2}{|c|}{ Pretest } & \multicolumn{2}{|c|}{ Post test } & \multirow{2}{*}{ Mean achievement Gain } \\
\hline Groups & $\mathrm{N}$ & Mean & SD & Mean & SD & \\
\hline Treatment & 127 & 21.3671 & 8.2356 & 59.2718 & 7.48 & 37.9047 \\
\hline Control & 143 & 19.1687 & 6.7432 & 40.2116 & 10.51 & 21.0429 \\
\hline
\end{tabular}

According to Table 1, results reveal that students taught by teachers who employed classroom interaction patterns (experimental group) perform better than those taught by teachers who employed conventional methods of teaching as shown by post test scores of 59.2718 and 40.2116 with achievement gain of 37.9047 and 21.0429 .

\section{Research Question 2}

What are the mean cognitive achievement scores of male and female students exposed to different interaction patterns?

Table 2. Mean and Standard Deviation (SD) for the Experimental group across the sex

\begin{tabular}{lllllllc}
\hline & \multicolumn{6}{c}{ Pretest } & \multicolumn{2}{c}{ Post test } & Mean achievement Gain \\
\hline Groups & Sex & N & Mean & SD & Mean & SD & \\
Treatment & Male & 58 & 20.2781 & 8.5816 & 54.4416 & 8.3215 & 34.1635 \\
& Female & 69 & 21.1568 & 7.4507 & 60.0226 & 6.6423 & 38.8658 \\
\hline
\end{tabular}

Table 2 result revealed the pretest mean scores and SD scores for the experimental male and female are 20.2781 and 8.5156; 21.1568 and 7.4507 respectively. Similarly, the post-test mean scores and SD scores for the experimental male and female are 54.4416 and 8.3215; 60.0226 and 6.6423. The mean achievement gain for male and female in the treatment group are 34.1635 and 38.8658 respectively.

Table 3. Summary of ANCOVA Table by method and gender

\begin{tabular}{llllll}
\hline Sources of Variation & Sum of Squares & df & Mean Squares & F & Fev $_{c}$ \\
\hline Covariance & 699.331 & 1 & 699.331 & 3.237 & \\
Main Effects & 54408.711 & 2 & 27204.355 & 125.927 & \\
Gender & 650.486 & 1 & 650.486 & 3.011 & 3.84 \\
T. method & 49284.172 & 1 & 49284.172 & 228 & 3.84 \\
2-way interaction (Gender \& T. method) & 715.725 & 1 & 715.725 & 3.313 & 3.84 \\
Explained & 55823.767 & 4 & 13955.942 & 64.601 & \\
Residual & 51415.863 & 268 & 216.033 & & \\
Total & 107239.630 & 270 & & & \\
\hline
\end{tabular}

From the hypothesis result across method, the ANCOVA table shows that F-cal (228) is greater than the critical value (3.84) at an alpha level of 0.05 . Therefore, since the calculated value is greater than the critical value, the null hypothesis was rejected. Hence, there is a significant difference in the mean achievement scores of students taught biology using classroom interaction pattern and those taught using the conventional method. The experimental group performed better than the control group.

For hypothesis result on difference across gender, Table 3 result reveal that F-cal (3.011) is less than Fcv (3.84) at an alpha level of 0.05. Since the calculated value is less than the critical value at the given alpha; the null hypothesis is not rejected. Therefore, there is no significant difference in the mean cognitive achievement scores of male and female students in biology due to application of classroom interaction patterns.

\section{Discussion}

The findings of this study showed that the treatment group obtained a higher mean cognitive achievement score as a result of their teacher 
application of classroom interaction patterns compared to their control group counterparts. The superiority of the treatment group over the control group is in agreement with the findings of researchers who had an innovative experimental treatment in their study (Aniekwe, 2002; [13].

In the case of gender, the findings of this study revealed that female students scored slightly higher than their male counterparts in BAT. That was further confirmed by the ANCOVA result in table 3 which revealed that gender was not a significant factor on students achievement in science. This result agrees with the findings of Okoyefi \& Nzewi [15]; Nnorom [10]; Ogunleye \& Babajide [14], who found no significant difference in the achievement of male and female students in science subjects.

\section{Conclusion}

The findings of this study have shown that application of classroom interaction patterns is a practically efficacious instructional strategy in enhancing students' cognitive achievement scores in mainsteam classrooms. Hence, application of classroom interaction pattern is a better instructional strategy than the conventional teaching methods. Also, it was concluded that although with the application of classroom interaction pattern female students score slightly higher than their male counterparts. The difference in the mean achievement scores of male and female taught biology using application of classroom interaction pattern is not statistically significant.

\section{Recommendations}

The following recommendations were made:

- The federal and state government should organized incentive laden in-service training programme for all serving science teachers, especially biology to impact knowledge of the theories of classroom interaction patterns on the teachers for dynamic and improved teaching.

- Science curriculum should be reviewed in terms of the basic instructional approach to incorporate integrative application of interaction pattern.

\section{References}

[1] Anaekwe, M.C. (2002). Effects of students' interaction patterns on cognitive achievement, retention and interest in chemistry. Unpublished Doctorate Dissertation. Department of Science Education, University of Nigeria Nsukka.

[2] Anderson, A. (2011). Learning strategies the missing thing in physics education and coaching: A practical guide to the development of strategies learners. Toronto: Sport Books publishers.
[3] Aniaku, O.L. (2012). Effect of guided and unguided inquiry teaching methods on secondary school students' achievement and interest in biology in Enugu State. Unpublished M.Sc Thesis University of Nigeria Nsukka.

[4] Anyaegbunam, N.J., Nwodo, B.I. \& Enibe, D.E. (2015). Effective application of constructivist theartre instruction (CTI) procedures for improving achievement and attitudes of biology students. Proceeding 56th Annual Conference of Science Teachers Association of Nigeria (STAN) Pg $102-111$.

[5] Awotua-Efeby, E.B. (2012). Effective teaching: Principle and practice. Port Harcourt: Paragraphics

[6] Mackey, A. (2013). The conventional interaction in second language acquisition. Oxford: oxford university press.

[7] Maduabum, M.A. (2012). The relative effectiveness of the expository and guided discovery methods in secondary school students' achievement in biology. Enugu State University of Science and technology Journal of Education. 1(1), 122-136.

[8] Maduabum, M. (2014). Students interest and achievement in biology: Some Correlates Journal of Curriculum and Instruction 3(1 \& 2) 10 -19.

[9] Metelo, A. (2005). Describing classroom interaction. Retrieved - Google: Hyperlink http: //www/salzburgsemer.org.asc/csacl/prog/interactive/ANA. htm

[10] Nnorom, N.R. (2013). Effects of reasoning skills on students' achievement in biology in Anambra State. International Journal of Scientific \& Engineering Research 4(12) 2104

[11] Nnorom, N.R. (2015). Effect of cooperative learning instructional strategy on senior secondary school students achievement in biology in Anambra State, Nigeria. International Journal for Cross Disciplinary Subjects in Education (IJCDSE). Special Issue 1/5 (1) 2424 - 2427.

[12] Nurmasita, S. (2010). Classroom interaction characteristics in Geography classes. M.ED Thesis, Diponegoro University

[13] Ogbu, J.E. (2011). Effects of interactive application patterns on students cognitive achievement in basic electricity. Journal of Science Teachers Association of Nigeria 46(1) $71-81$.

[14] Ogunleye, B.O. \& Babajide, E.A. (2011). Commitment to science and gender as determinants of science achievements and practical skills in physics. Journal of Science Teachers Association of Nigeria. 46(1) $125-136$

[15] Okoyefi, Q.O. \& Nzewi, U.M. (2015). Effect of material and nonmaterial reinforcement on pupils' achievement in basic sciences. STAN Journal 50(1), $40-$ 47. 
[16] Omoniyi, O.A. (2006). The effect of constructivist based teaching strategy on gender-related differences in students' misconceptions in chemistry. Ministry of Education Akure: Nigeria.

[17] Opara, J.A. (2011). Inquiring method and students' academic achievement in biology: lessons and policy implications; American Eurasian Journal of Scientific Research, 6(1), $28-31$.

[18] Shomoossi, N. (2004). The effect of teachers questioning behaviour on classroom interaction: A classroom research study. The reading matrix 4(2) 96-104.

[19] West African Examination Council (2010 - 2015). Chief examiner's reports. SSCE, May/June Yaba Lagos: WAEC.

[20] West African Examination Council (2015). Analysis of result, Lagos: WAEC. 